\title{
Science of umami taste: adaptation to gastronomic culture
}

Kumiko Ninomiya

\begin{abstract}
This paper reviews the points behind the more than a hundred-year delay for the acceptance of umami as a basic taste along with the sweet, sour, salty, and bitter tastes after its discovery by a Japanese scientist in 1908. One of the main reasons for the late recognition of umami taste is the difference in culinary culture between Europe and Japan. Recent collaborative studies with chefs and researchers on traditional soup stocks showed different taste profiles for the Japanese soup stock 'dashi' and the western-style soup stock. The profile of free amino acids in dashi, when compared to the one in the Western style soup stock, explains why umami has been more easily accepted by Japanese who have being traditionally experiencing the simple umami taste of dashi. The recent exchange on cooking methods and diverse types of umami-rich foods in different countries has facilitated a new approach to culinary science blending culinary arts, food science, and food technology for healthier and tastier solutions.
\end{abstract}

Keywords: Umami, Glutamate, Inosinate, Guanylate, Amino acids, Soup stock

\section{Introduction}

Umami is the taste imparted by a number of substances, predominantly the amino acid glutamate and 5 '-ribonucleotides such as inosinate and guanylate. After the discovery of umami by Kikunae Ikeda in 1908 [1], almost 100 years were required to obtain a global scientific recognition of umami as one of the basic tastes together with sweet, sour, salty, and bitter. The original idea of researching on glutamate occurred to Kikunae Ikeda when studying physical chemistry in the laboratory of Wilhelm Ostwald in Leipzig, Germany [2]. During his stay in Germany (from 1899 to 1901), he found that there was a quite peculiar and subtle taste common in tomato, asparagus, cheese, meat, etc., which he first experienced in Germany. Ikeda recognized that there were four well-defined taste qualities, sweet, sour, salty, and bitter. However, he also considered the possibility of an additional taste quality, which was quite distinct from the well-known four basic tastes. After returning to Japan and tasting again the traditional soup stock dashi made from dried seaweed konbu (Laminariaceae Bory), he realized that dashi hold the same taste he had

Correspondence: Kumiko04221846@gmail.com

Umami Information Center, 8-7-1202 Nibancho, Chiyoda-ku, Tokyo 102-0084, Japan experienced in German foods. As a result, he began a study to identify the key chemical component in konbu responsible for this unique taste. After a long chemical process, Ikeda isolated glutamic acid from konbu. Then, he prepared and tasted glutamate in the form of salts of $\mathrm{Na}, \mathrm{K}$, and $\mathrm{Ca}$. His understanding was that glutamic acid should be present almost exclusively as a salt in konbu. The salts of glutamic acid presented a unique taste that he named umami. At the time Ikeda started his research, glutamic acid was not a new amino acid; it had been first isolated from wheat protein by Ritthausen in 1866, and Fischer subsequently reported its taste as sour at first, becoming peculiar and insipid later [3,4]. As a result, Fisher found no reason to study the sensory properties of glutamic acid. Ikeda completed his work in 1908 and he presented a paper 'On the taste of the salt of glutamic acid' at the International Congress of Applied Chemistry which was held in the US in 1912 [5].

In 1913, Ikeda's disciple Shintaro Kodama identified $5^{\prime}$-inosinate (salt of inosine-5'-monophosphate) as the umami substance in dried bonito, which have been also traditionally used for cooking dashi in Japan [6]. In 1957, 5 '-guanylate was also shown to elicit an umami taste by Akira Kuninaka and was found to be the major umami substance in dried shiitake mushrooms [7]. Kuninaka 
was the first to explain that the combination of glutamate with $5^{\prime}$-nucleotides, such as inosinate or guanylate, greatly enhances the effect of glutamate and in turn the intensity of umami taste [8]. Today, the phenomena of synergism is widely recognized and practiced worldwide, such as the combination of konbu with dried bonito in dashi, or by mixing vegetables and meat or fish in various soup stocks.

\section{Two great inventors in Europe and Japan}

After the discovery of umami, Ikeda and Saburosuke Suzuki, an iodine manufacturer, developed in 1909 a new seasoning, monosodium glutamate (MSG), to simply add umami taste, the key taste compound of dashi, to a wide variety of Japanese home-cooked dishes [8]. Suzuki's business was to sell iodine extracted from seaweeds as medicine. Ikeda's original idea was to have Suzuki's patronage the extracting of glutamic acid from seaweeds and develop a new seasoning, MSG. However, the contents of glutamic acid in wheat protein is much higher than that in seaweed, so he decided to develop a mass-production process for MSG from hydrolysate of wheat protein. The production process of MSG by Ikeda was quickly patented in Japan, US, UK, and France [9]. Before the discovery of umami, he read a paper written by the first Japanese medical doctor, Hiizu Miyake, claiming that 'good taste promotes digestion of foods.' Miyake's theory prompted the invention of the new seasoning MSG by Ikeda that could be easily used in the kitchen to improve the taste of home-cooked meals just like salt and sugar. The passion of Ikeda was to improve the nutritional status of the Japanese population.

It is interesting to look into the history of industrial manufacture of soups, which is one of the most basic savory foods in Europe. Julius Maggi [10], a pioneer in the food industry in Europe, produced appliances for roasting and grinding beans to make flour from peas, beans, lentils, etc. His objective was to provide nutritious and flavorful rapid-cooking dehydrated soups for workingclass women who lacked the time and money to prepare proper home-cooked soups. In fact, many housewives started working in his factory. He worked with the physician Fridolin Schuler who held the concept of improving the nutritional content of meals for the laboring classes by making packaged foods with a new soup product. The first industrially produced ready-to-use soups based on hydrolysate was introduced in the Swiss market in 1886, followed by various kinds of soups in cubes in 1908. At that time, it was not known that one of the important taste components of these soups was umami.

The two great inventors in the Far East and the West, Ikeda and Maggi, respectively, developed new products with the purpose of improving nutrition at approximately the same time. Each of the two inventors happened to use hydrolysate proteins to produce new products. Ikeda isolated glutamic acid from hydrolysate of wheat protein, but Maggi used a free amino acids mixture based on hydrolyzed proteins from beans. It is evident that these inventions reflect the different food cultures of soup stocks in Japan and Europe. Glutamate is the most abundant amino acid among the only few free amino acids found in the Japanese soup stock made from konbu (Figure 1). On the other hand, there is a variety of free amino acids found in European soup stocks made from meat and vegetables (Figure 2). The taste of Japanese soup stock made from konbu has a clearer umami taste compared to the one of the European soup stock that presents a complicated taste with the mixture of various free amino acids including the umami taste of glutamate.

\section{The long road to the global acceptance of umami taste}

As it is mentioned earlier, the first presentation on the discovery of umami was given by Ikeda in 1912 in the USA. The presentation on 'The Umami Taste' by Shizuko Yamaguchi in the International symposium on food taste chemistry, which was jointly organized in 1979 by the American Chemical Society and the Chemical Society of Japan in Hawaii, was an important step to introduce the fundamental concept of umami taste in sensory science as well as the use of 'umami' as a scientific term [11]. After this presentation, many researches started conducting studies on umami taste not only in Japan but also in the USA and Europe within multidisciplinary fields including food science, nutrition, physiology, brain science, etc. Since pure umami by simple aqueous solutions of MSG, IMP, and GMP was difficult to describe, especially for people outside of Japan, there were many discussions on whether umami was a basic taste or not. Gary Beauchamp summarized results of early studies on the use of MSG in foods conducted in the USA. He realized that humans found umami compounds unpalatable when tasted alone, while they improved the taste of foods when mixed with other ingredients [12]. In the First International Symposium on Umami held in Hawaii in 1985, Michael O'Mahony introduced the results of the description on the taste qualities of an MSG solution by Japanese and American subjects. More than $50 \%$ of Japanese subjects answered that the taste of an MSG solution was umami, while only $10 \%$ of American subjects answered that MSG tasted umami. More than $40 \%$ of the American subjects described the taste of the MSG solution as salty and the remaining $10 \%$ said that MSG holds an 'indefinite taste' [13]. Since dashi, which has a simple umami taste, is the fundamental soup stock used to cook a variety of Japanese dishes, it is easy for Japanese people to associate the taste of MSG solution with the umami taste in dashi. In contrast, the perception of a clear umami taste is not common in Western cultures, most likely because 


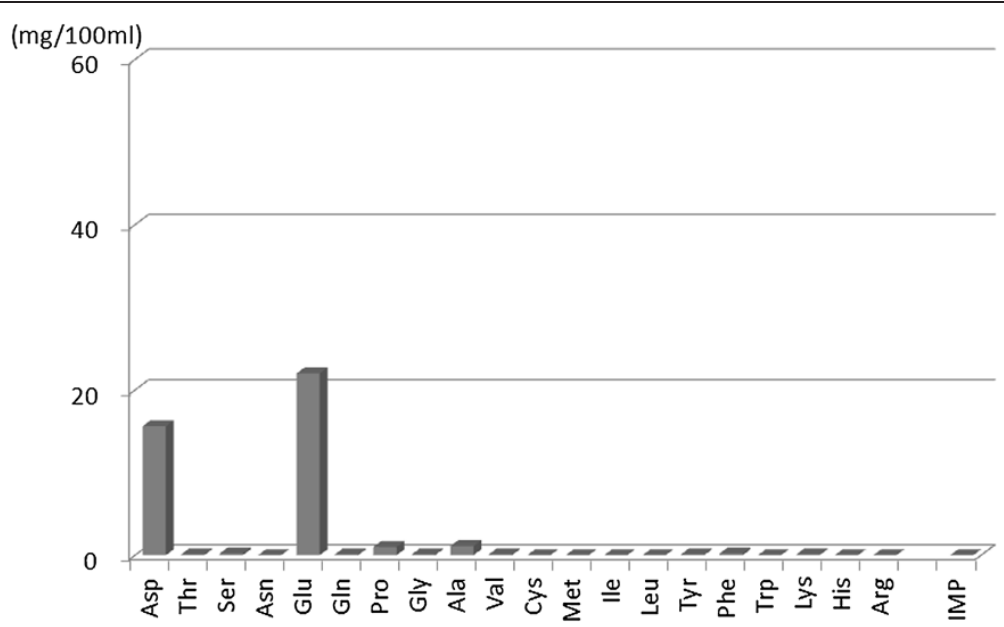

Figure 1 Free amino acids and inosinate in Japanese soup stock 'dashi'. Dashi was cooked based on the recent cooking method introduced by the Japanese chefs' organization in Kyoto. $20 \mathrm{~g}$ of rishiri konbu was cooked at $60^{\circ} \mathrm{C}$ for $1 \mathrm{~h}[15]$.

until recently the Western cuisine has not used pure, umami-rich ingredients. Discussion of the key issues pertaining to the establishment of umami as a basic taste lasted until the discovery of human umami taste receptors that was published in 2002 [14].

Recently, umami has spread widely not only in the scientific field but also in gastronomy. Nowadays, cooks and chefs from the culinary arts are able to express accurately the unique characteristics of umami taste using their own words (Table 1) [4]. Trends on collaborative works between chefs and researchers over the past two decades have allowed for blending science and cooking. This has accelerated the deepening and broadening of umami knowledge. It has taken almost 100 years for the global and scientific recognition of umami taste as one of the five basic tastes, but with the support of science and gastronomy, it has become a key element in taste physiology and culinary arts.

\section{The same goal but following a different path}

Traditional soup stocks from different countries such as Japanese soup stock dashi and Western style soup stocks hold a different taste profile. The cooking of a soup stock consists of extracting a variety of taste substances including umami substances. Free glutamate is one of the major amino acids found in various types of soup stocks, and it is rapidly extracted from food ingredients in the early stages of cooking. Soup stocks in Western

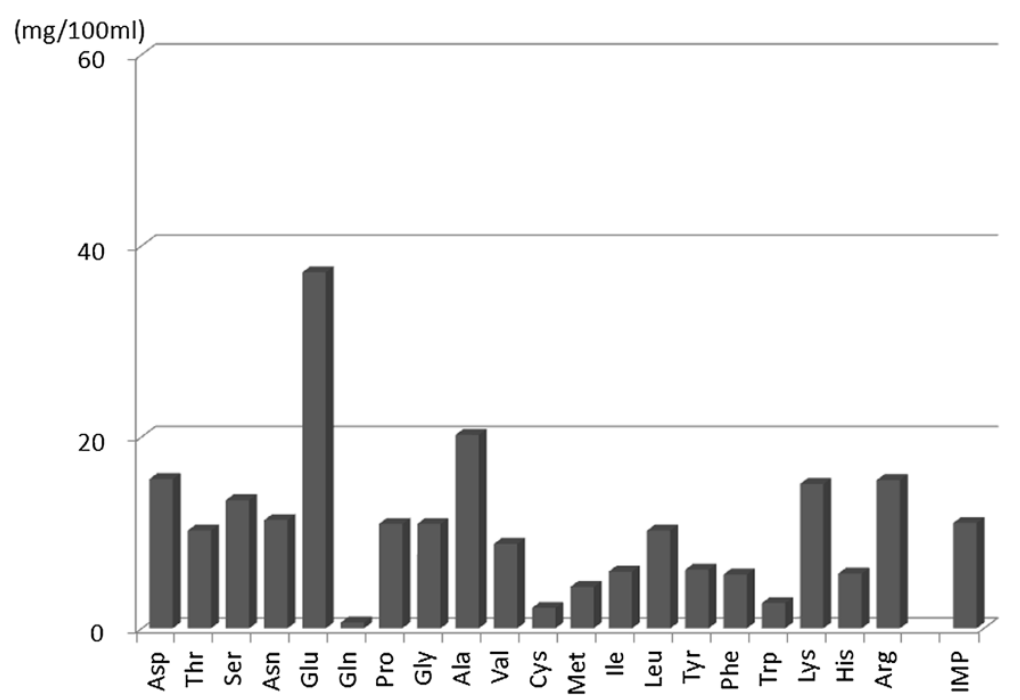

Figure 2 Free amino acids and inosinate in chicken bouillon. Raw materials and preparation of the bouillon were based on the standard method used in the Tsuji Culinary Institute of Abeno, Osaka, Japan [3]. 
Table 1 Expression of umami by culinary professionals

Savory

Delicate and subtle

Mellow sensation

Earthy, musty, and mushroom-like taste

Taste like a big meaty and mouthful

It makes your mouth water

Mouth watering

Pleasant after taste with satisfaction

Lingering sensation

Subtle and ambiguous

Full tongue and coating sensation

Fullness of taste and that filled my mouth

It provide deep flavor and harmony balance

Ninomiya et al. [3] and Umami Information Center [4].

countries rely on a long cooking process for the extraction and concentration of taste substances from food ingredients such as meat, poultry, or fish, and vegetables. As a result, umami harmonizes with the overall flavor [3]. In Japan, food ingredients that are especially high in umami, such as dried seaweed konbu and dried bonito, are used for cooking the Japanese soup stock dashi. Konbu is dried slowly over a long period of time to remove moisture and unfavorable odor, and boiled fillet of bonito is smoked and sprayed with a mold culture (Aspergillus glaucus) to make the hardest food in the world. Umami is concentrated in advance in these food ingredients. Because of the unique and long process of making dried konbu and bonito for Japanese soup stock dashi, umami can be rapidly extracted during cooking.
Thus, cooking time for Japanese soup stock dashi is considerably shorter, less than $1 \mathrm{~h}$ than in Western soup stock. There are only a few amino acids in Japanese soup stock including glutamate and aspartate. The major amino acids in Western soup stocks are glutamate, alanine, and arginine besides other amino acids [15]. Neither approach is superior to the other; both are different ways of achieving the same goal. Although the free amino acid profile of dashi is simpler than Western soup stock, miso, fermented soybean paste, adds a variety of free amino acids in the process of cooking miso soup. It is interesting to note that a proportion of free glutamate and aspartate in the total free amino acid content in miso soup and consommé is quite similar as shown in Figure 3. The proportion of glutamate in relation to the other free amino acids in soups is the same.

\section{Conclusion and future outlook}

Using umami taste in a low-salt diet increases the palatability of the foods [16]. Chefs who understand umami taste realized that umami keeps the palatability of dishes even though the concentration of salt is lower than usual. Although there is no scientific data yet to back up the effect of umami in low-fat foods, experiences with chefs suggest that umami compounds may have the ability to improve the palatability of low-fat foods like it does with low-salt foods. Utilizing the taste-enhancing properties of umami to improve the acceptability and palatability of food is beneficial for meals served in hospitals and nursing homes for the elderly $[17,18]$.

The exchange of knowledge on cooking methods and diverse types of umami-rich foods in different countries has made it possible to design new combinations of
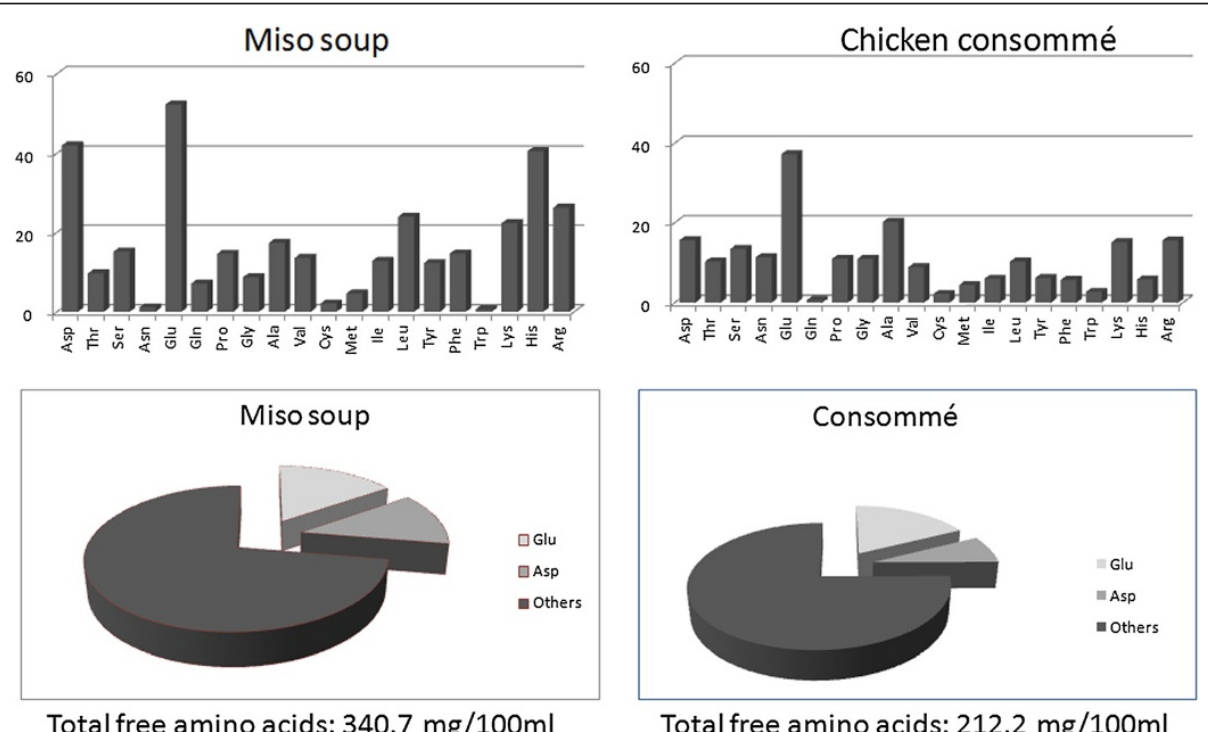

Figure 3 Comparison of free amino acids in miso soup and chicken consommé [15]. 
ingredients for the creation of a new style of soup stock. Recent studies showed that eating umami-rich foods is helpful to improve the severe condition of dry mouth in elderly people, because umami promotes salivation [19]. The total amount of saliva secretion that results from umami taste stimuli is larger than that by sour taste [20]. There are studies that apply the taste-enhancing properties of umami to improve the acceptability and palatability of meals for the elderly in nursing homes that were conducted in both Japan and the UK $[4,21]$. The most recent studies on the effect of umami taste on appetite and satiety suggested that adding umami, MSG, and IMP to a high-protein soup enhanced the satiety signal of proteins [22]. These scientific approaches as well as chefs' approach to use umami could not only tackle the challenge of healthy eating, but it could also adapt to the taste preference of every gastronomic culture.

\section{Competing interests}

The author declares that she has no competing interests.

\section{Authors' information}

Kumiko Ninomiya, PhD is the director of Umami Information Center which is non-profit organization based in Tokyo, Japan.

\section{Acknowledgements}

The author wishes to thank Ana San Gabriel and Hiroya Kawasaki for helpful discussion on the science of umami taste.

Received: 2 December 2014 Accepted: 2 December 2014

Published: 26 January 2015

\section{References}

1. Ikeda K: New seasonings. Chem Senses 2002, 27:847-849 [Translation of J Chem Soc Jpn 1909, 30:820-836.

2. Kurihara K: Glutamate: from discovery as a food flavor to role as a basic taste (umami). Am J Clin Nutr 2009, 90(suppl):719-722.

3. Ninomiya K, Kitamura S, Saiga-Egusa A, Ozawa S, Hirose Y, Kagemori T, Moriki A, Tanaka T, Nishimura T: Changes in free amino acids during heating bouillon prepared at different temperatures. J Home Economics Jpn 2010, 61:765-773.

4. Umami Information Center: Umami The Fifth Basic Taste. Tokyo: Japan Publications Co., Ltd: 2014.

5. Ikeda K: On the taste of glutamate. In Abstracts for the 8th International Congress of Applied Chemistry. Washington and New York: 1912:147.

6. Kodama S: On a procedure for separating inosinic acid. J Tokyo Chem Soc 1913, 34:751-757.

7. Kuninaka A: Studies on taste of ribonucleic and derivatives. J Agric Chem Soc Jpn 1960, 34:489-492.

8. Kuninaka A: The nucleotides, a rationale of research on flavor potentiation. In Proceedings of the Symposium on Flavor Potentiation. Cambridge: By Arthur D. Little; 1964:4-9.

9. Sano C: History of glutamate production. Am J Clin Nutr 2009, 90(Suppl):728-732

10. Heer J: Nestle 125 Years, 1866-1991. Nestle, SA: Vevey, Switzerland; 1991.

11. Yamaguchi S: The umami taste. In Food Taste Chemistry. Edited by Boudoreau JC. Washington DC: American Chemical Society; 1979:33-51.

12. Beauchamp GK: Sensory and receptor responses to umami: an overview of pioneering work. Am J Clin Nutr 2009, 90(Suppl):723-727.

13. O'Mahony M, Ishii R: The umami taste concept: implications for the dogma of four basic tastes. In Umami: a basic taste. Edited by Kawamura $Y$, Kare MR. New York and Basel: Marcel Dekker, Inc; 1987:75-96.

14. Li X, Staszewske L, Xu H, Durick K, Zoller M, Adler E: Human receptors for sweet and umami taste. Proc Natl Acad Sci USA 2002, 99:4292-4296.
15. Ninomiya K: Research on soup stock in Japanese and Western cuisine, PhD thesis. Hiroshima University: Faculty of Applied Biological Science; 2010.

16. Yamaguchi S, Ninomiya K: Umami and food palatability. J Nutr 2000, 130(Suppl):921-926.

17. Bellisle F, Monneuse O, Chabert M, Larue-Achagiotis C, Lanteaume MT, Louis-Sylvestre J: Monosodium glutamate as a palatability enhancer in the European Diet. Physiol Behav 1991, 49:869-873.

18. Yamamoto $\mathrm{S}$, Tomoe $\mathrm{M}$, Toyama $\mathrm{K}$, Kawai $\mathrm{M}$, Uneyama H: Can dietary supplementation of monosodium glutamate improve the health of the elderly? Am J Clin Nutr 2009, 90(Suppl):844-849.

19. Satoh-Kuriwada S, Shoji N, Kawai M, Uneyama H, Kaneta N, Sasano T: Hyposalivation strongly influences hypogeusia in the elderly. $J$ Health Sci 2009, 55:689-698.

20. Hodson N, Linden R: The effect of monosodium glutamate on parotid salivary flow in comparison to the response to representatives of the other four basic taste. Physiol Behav 2006, 89:711-717.

21. Sasano T, Satoh-Kurwada S, Shoji N, likubo M, Kawai M, Uneyama H, Sakamoto M: Important role of umami taste sensitivity in oral and overall health. Curr Pharm Design 2014, 20:2750-2754.

22. Masic U, Yeomans MR: Umami flavor enhances appetite but also increases satiety. Am J Clin Nutr 2014, 100:532-538.

doi:10.1186/2044-7248-4-13

Cite this article as: Ninomiya: Science of umami taste: adaptation to gastronomic culture. Flavour 2015 4:13.

\section{Submit your next manuscript to BioMed Central and take full advantage of:}

- Convenient online submission

- Thorough peer review

- No space constraints or color figure charges

- Immediate publication on acceptance

- Inclusion in PubMed, CAS, Scopus and Google Scholar

- Research which is freely available for redistribution
C Biomed Central 